\title{
HOME RANGES OF \\ MALE CERCERIS SIMPLEX MACROSTICTA \\ (HYMENOPTERA, SPHECIDAE)*
}

\section{By John Alcock and George Gamboa}

Department of Zoology, Arizona State University, Tempe 8528I ; and Department of Zoology, University of Iowa, Iowa City, $522+2$.

Although it is well known that many sphecid males visit flowers and shrubs and attempt to mate with females found there (e.g. Peckham, Kurczewski, \& Peckham, I973), many unanswered questions about this general pattern of male behavior remain. For example, do flower-visiting males move randomly from area to area or do they remain in one location for substantial periods of time? If they show an attachment to a particular site, do they defend the area or do they share it with other males?

We addressed these questions for one species by studying males of Cerceris simplex macrosticta Viereck and Cockerell at two separate sites along State Line Rd., $1 / 2 \mathrm{~km}$ west of Rodeo, New Mexico. Study area I consisted of a strip of roadside ditch, $75 \mathrm{~m} \times 2 \mathrm{~m}$, covered with a dense stand of flowering milkweeds (Asclepias subverticillata). Two mesquites and a sprawling multiflora rosebush were the only large plants at this location. Study site 2, located several hundred meters from study site I, was an area roughly $25 \mathrm{~m} \times 10 \mathrm{~m}$ in an uncultivated pear orchard overrun with clumps of Russian thistle (Salsola kali) and dotted with scattered flowering weeds. From 23-27 July 1974 sixteen males were captured in these two areas and marked on the dorsum of the thorax with acrylic paints, each individual receiving a distinctive color or color combination. One or more censuses were made at the two sites on all days from 23 July to 8 August with the exception of 2, 4, and 7 August.

\section{Results}

Home ranges of $C$. simplex

Nine of the marked males were seen again at or near the location where they had been originally captured and seven of the sixteen males were followed for a week or more (Table I). The failure to relocate six marked individuals could be attributed to a variety of factors including mortality and the passage of transient males from the study areas.

*Manuscript received by the editor January 20, 1975. 
Table 1. Site attachment of male $G$. simplex. A total of sixteen individuals marked 23-27 July.

\begin{tabular}{|c|c|c|c|c|c|c|c|c|c|c|}
\hline \multicolumn{11}{|c|}{ Days At Site } \\
\hline 1 & 2 & 3 & 4 & 5 & 6 & 7 & 8 & 9 & 10 & 11 \\
\hline \multicolumn{11}{|c|}{ Number of Wasps } \\
\hline 6 & 1 & 1 & & & & 1 & 2 & 1 & 2 & 2 \\
\hline
\end{tabular}

The resident males were repeatedly observed pursuing regular circuits between $0839-\mathrm{I} 230 \mathrm{hrs}$. and rarely as late as I400 M.S.T. Four carefully studied individuals possessed routes ranging from 7.0-18.5 $\mathrm{m}$ in length and from $2-3 \mathrm{~m}$ in width (Fig. $\mathrm{I}$ ). However, marked wasps also made occasional forays up to six $m$ from their customary route. Males in the roadside ditch cruised in a fairly rapid and erratic flight going down one side of the ditch skimming over flowering Asclepias, and then back up the other. Orchard males flew from one clump of Salsola to another sailing around and over them, sometimes visiting flowering weeds along the route (Fig. I).

Wasp "yellow" had the smallest circuit of the males we studied and required a mean of $32 \mathrm{sec}$ to complete one flight about its home range ( $N=9$; range, 22-68 sec; 28 July, o820-I I I 5). Most of a male's time was spent in flight, although the wasps regularly alighted on perches in their cruising area (Fig. 2). For example, "white" landed on one branch of a rose bush 16 times in 35 minutes (23 July) remained perched an average of $6: 5 \mathrm{sec}$ (range, I-I9 sec). Several males had a primary perch to which they commonly returned as well as several secondary perches that were used less frequently.

Males pursued any medium-sized flying insect including a wide variety of wasps, beeflies, and brilliant black and red hemipterans as well as male and female conspecifics. Males made physical contact only with conspecific females. The indiscriminate nature of the pursuit flight and the absence of grappling or contact between males leads us to believe that male $C$. simplex lack behavior designed to defend a territory. The great overlap in routes travelled by different males (at least four males regularly entered "blue's" circuit and easily that many were present in "white's" area) further suggests that males of this species occupy home ranges and not territories.

Attempted matings

Despite many hours of observation, attempted copulations were seen only three times (at 0915, 0925, I030), all in the orchard. In one case a female cruised slowly through a Salsola clump occa- 


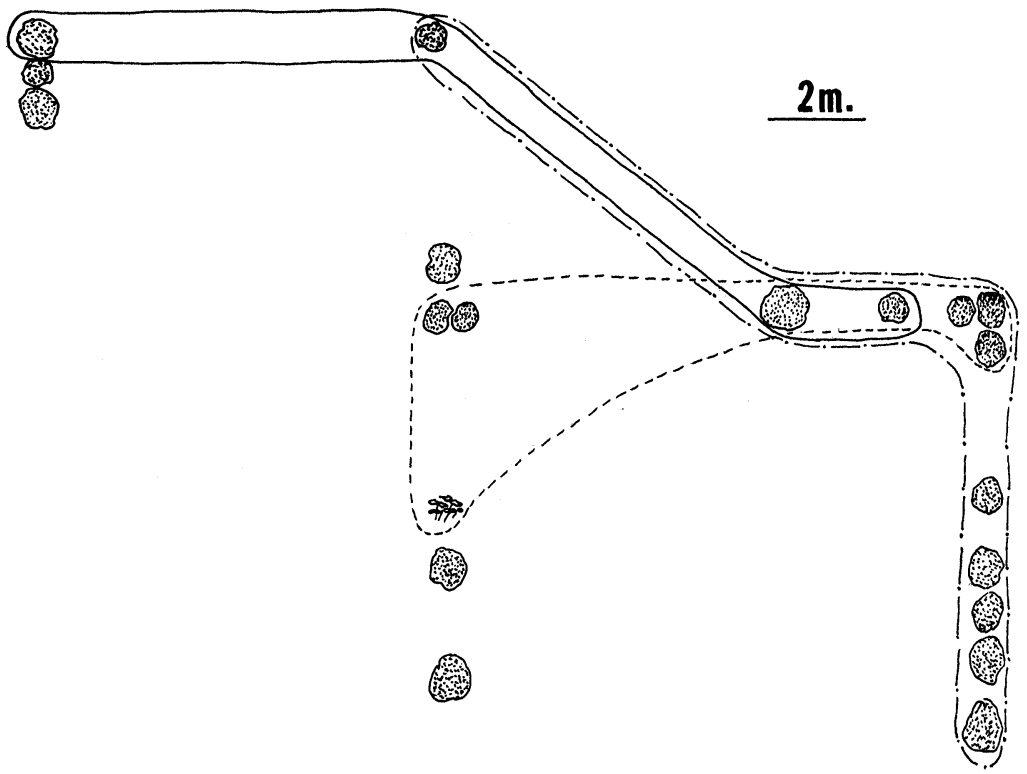

Fig. 1. The overlapping home ranges of three males at the orchard study area. "Blue's" home range is outlined with a dashed line; "red's" home range is outlined with a dot-dashed line; "white-dot's" home range is outlined with a solid line. The circular stippled areas represent prominent Salsola bushes. One large flowering weed is shown schematically in the lower left hand corner of "blue's" home range.

sionally alighting and walking up stems apparently searching for prey, the tenebrionid beetle Metapoloba pruinosa (Alcock, 1974), which were sometimes seen in this plant. As she flew slowly past a perched male he flew up and cruised behind her. The female alighted and the male quickly dropped onto her back facing in the same direction as his potential mate. While stroking her antennae with his the male held the female's wings out at right angles to her body by sandwiching each wing between his fore- and midlegs, presumably making escape more difficult for the female. His hindlegs grasped the female's abdomen. After several minutes of unsuccessful attempts to copulate, the male released his partner and both flew away. The other two attempted matings also followed this general pattern. One took place in a Salsola plant, the other on a flower head of a weed. The related wasp $C$. frontata also mates at flowers, initially adopting the position used by $C$. simplex (pers. obs.) with the male dismounting after coupling is achieved (Scullen, 1965). 
Sleeping sites

In the late afternoon, especially before impending storms, males were seen flying slowly along the large rose bush. The wasps eventually alighted and walked under groups of tightly packed leaves and, in one case, into a tube formed by a rolled leaf, evidently in search of a sheltered sleeping site. One male ("red") that had been marked on the morning of 27 July at a spot $50 \mathrm{~m}$ to the south of the rose bush was found by this plant at i6ro seeking a resting place before a thunderstorm. The next morning it had returned to the area where it had been marked indicating that some males may fly modest distances from their home range in order to exploit a sleeping site.

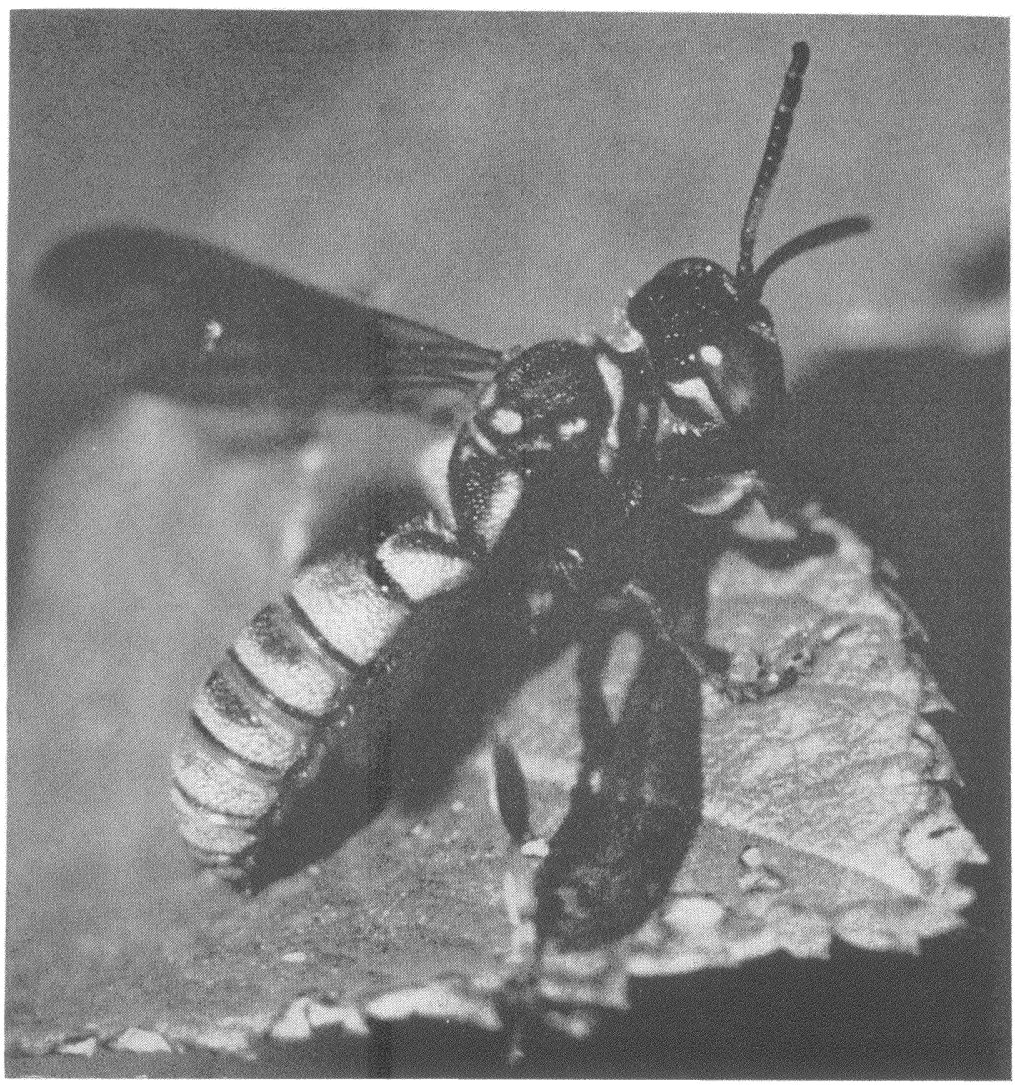

Fig. 2. A male Cerceris simplex perched on a rose leaf and resting between cruising flights about its home range. 


\section{Discussion}

To the best of our knowledge $C$. simplex provides the only documented example of a wasp species whose males occupy fairly extensive home ranges in areas away from an aggregation of nesting females. Doubtless this only reflects the lack of research of male wasps and it is probable that home ranges embracing patches of flowers are a common phenomenon in male sphecids.

The spacing system of male $C$. simplex does, however, differ from that of various close relatives, among them several species of Eucerceris as well as Philanthus and Clypeadon (Alcock, 1975 and in prep.). Males of these related species form relatively dense aggregations with each individual applying an attractant pheromone from abdominal glands to a perch and vigorously repelling all intruders from an area roughly $1 / 2-1 \mathrm{~m}$ in radius around the perch. Whether all the members of one genus share the same basic mating strategy is unknown and will require much further study, although the very limited current information hints that this may be the case (Alcock, in prep.).

Despite the differences between $C$. simplex and other philanthinine wasps there are some similarities as well. In all cases males occupy a perch to which they return after bouts of flying around. All pursue a remarkably wide range of flying insects evidently in an effort to determine the species and sex of the passerby or intruder. The key variable between different species is the area inspected by an individual. Those males that use a perch as a calling post defend it and a small area around it while $C$. simplex, which does not appear to employ an attractant pheromone, covers a much larger area (up to at least $4 \mathrm{O} \mathrm{m}^{2}$ ), so large as to be essentially indefensible. Attempts to drive all other males from a strip of roadside ditch $15 \mathrm{~m} \times 2 \mathrm{~m}$ would require an extraordinary investment in aggressive territorial patrolling. Instead, C. simplex males make no special effort to locate and repel conspecific males. Time and energy are devoted to repeated investigation of a large area in a location likely to attract females, one which is rich in nectar-producing flowers or beetleproducing bushes. Having found a potentially good area, males remain there becoming familiar with its prime spots. Presumably this is a superior strategy than one that would take a male on a random journey through the countryside in search of a mate. Because naturally occurring attractants (e.g. flowers) that draw in females tend to be patchily distributed, one would predict that males of other species that use such attractants to focus their search for females will 
also possess home ranges. Additional comparative data based on studies of marked populations of males are required to test this prediction.

\section{ACKNOWLedgments}

We thank Dr. Howard E. Evans for his review of a draft of this paper. This study was supported by National Science Foundation Grant GB-42865.

\section{REFERENCES}

Alcock, J.

1974. The nesting behaviour of Cerceris simplex macrosticta (Hymenoptera: Sphecidae). J. Nat. Hist., 8: 645-652.

1975. Territorial behaviour by males of Philanthus multimaculatus (Hymenoptera: Sphecidae) with a review of territoriality in male sphecids. Anim. Behav., in press.

Peckham, D. J., F. E. Kurczewski \& D. B. Peckham

1973. Nesting behavior of Nearctic species of Oxybelus (Hymenoptera: Sphecidae). Ann. Ent. Soc. Amer., 66: 647-661.

Scullen, H. A.

1965. Review of the genus Cerceris in America north of Mexico (Hymenoptera: Sphecidae). Proc. U. S. Nat. Mus., 116:333-548. 

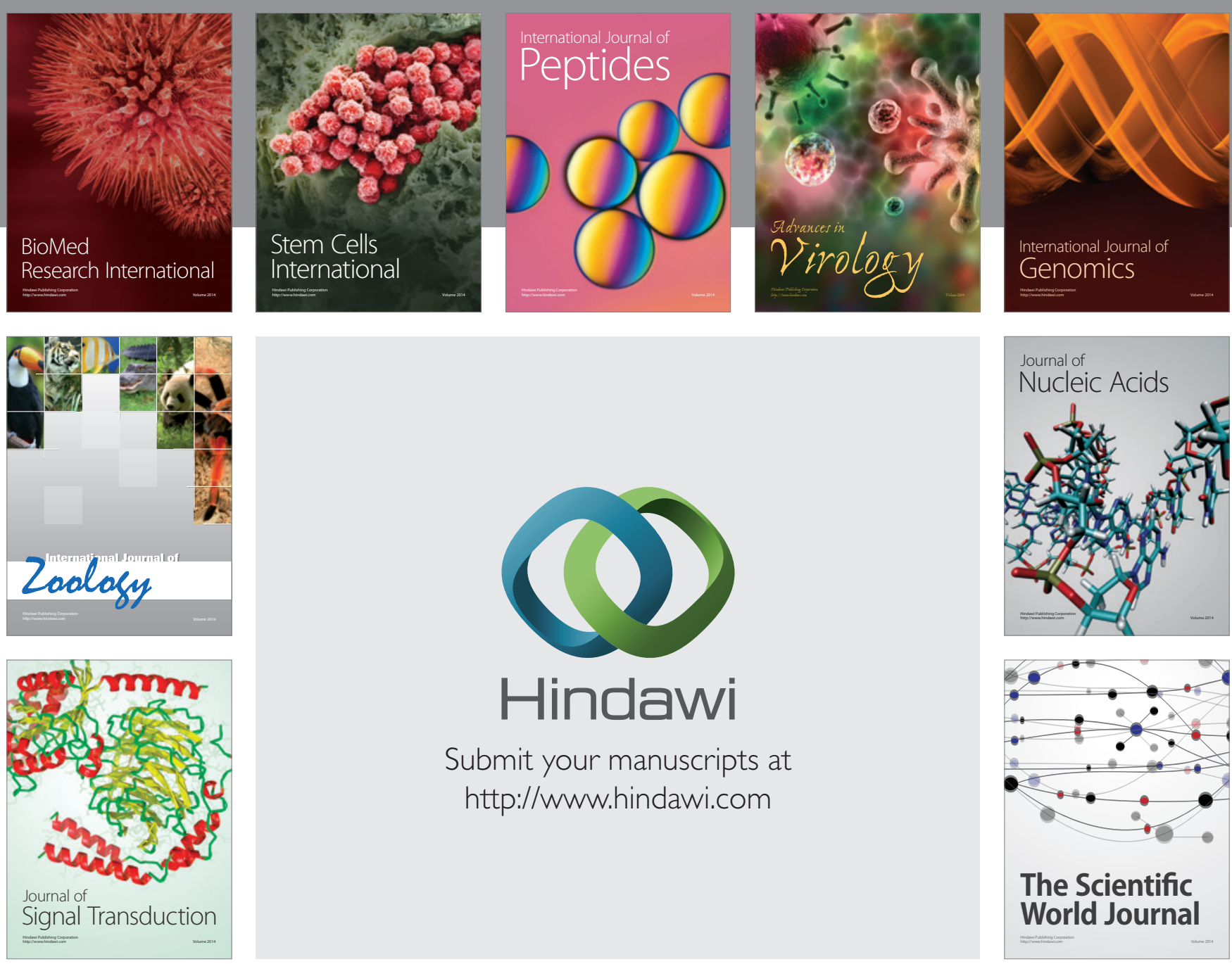

Submit your manuscripts at

http://www.hindawi.com
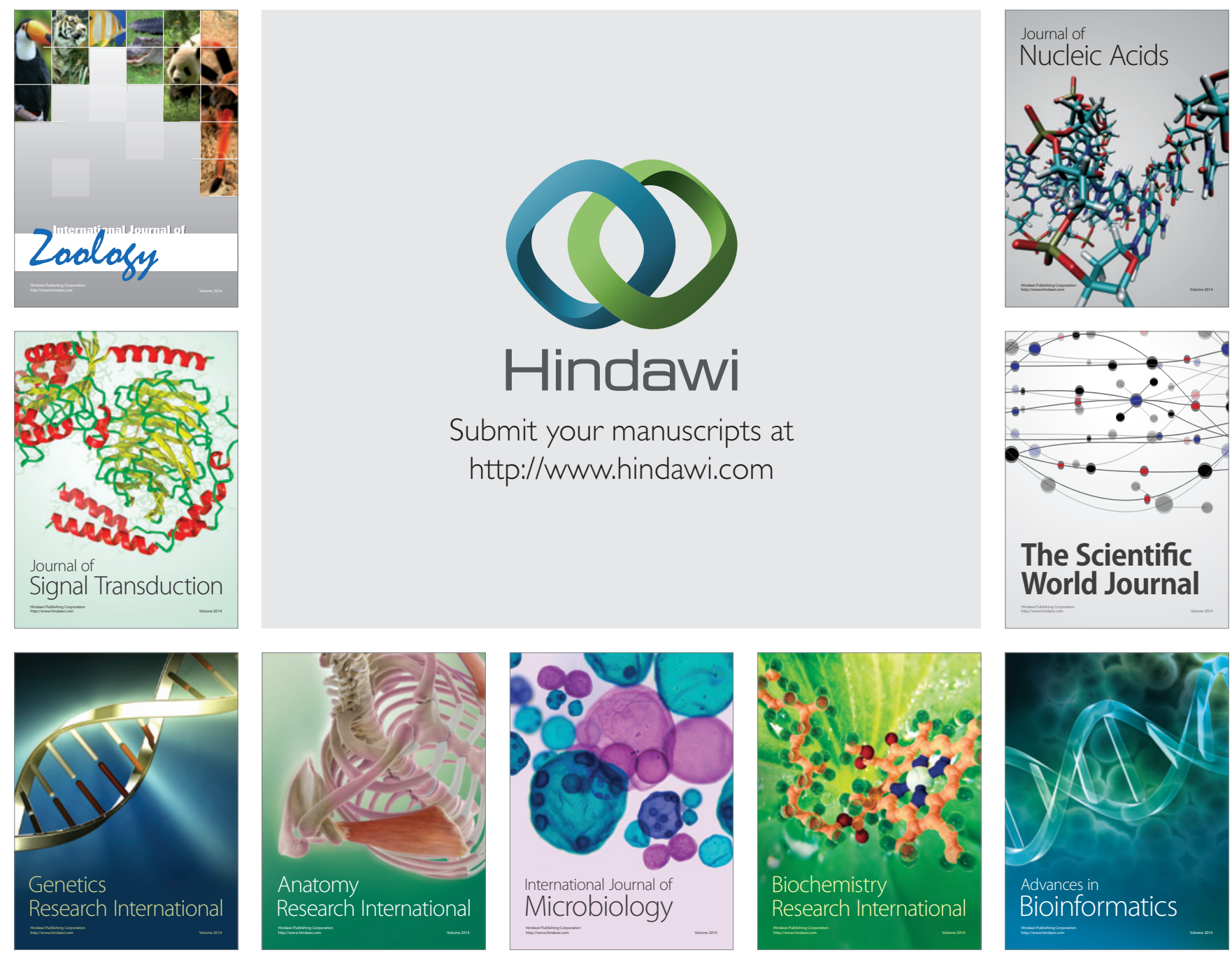

The Scientific World Journal
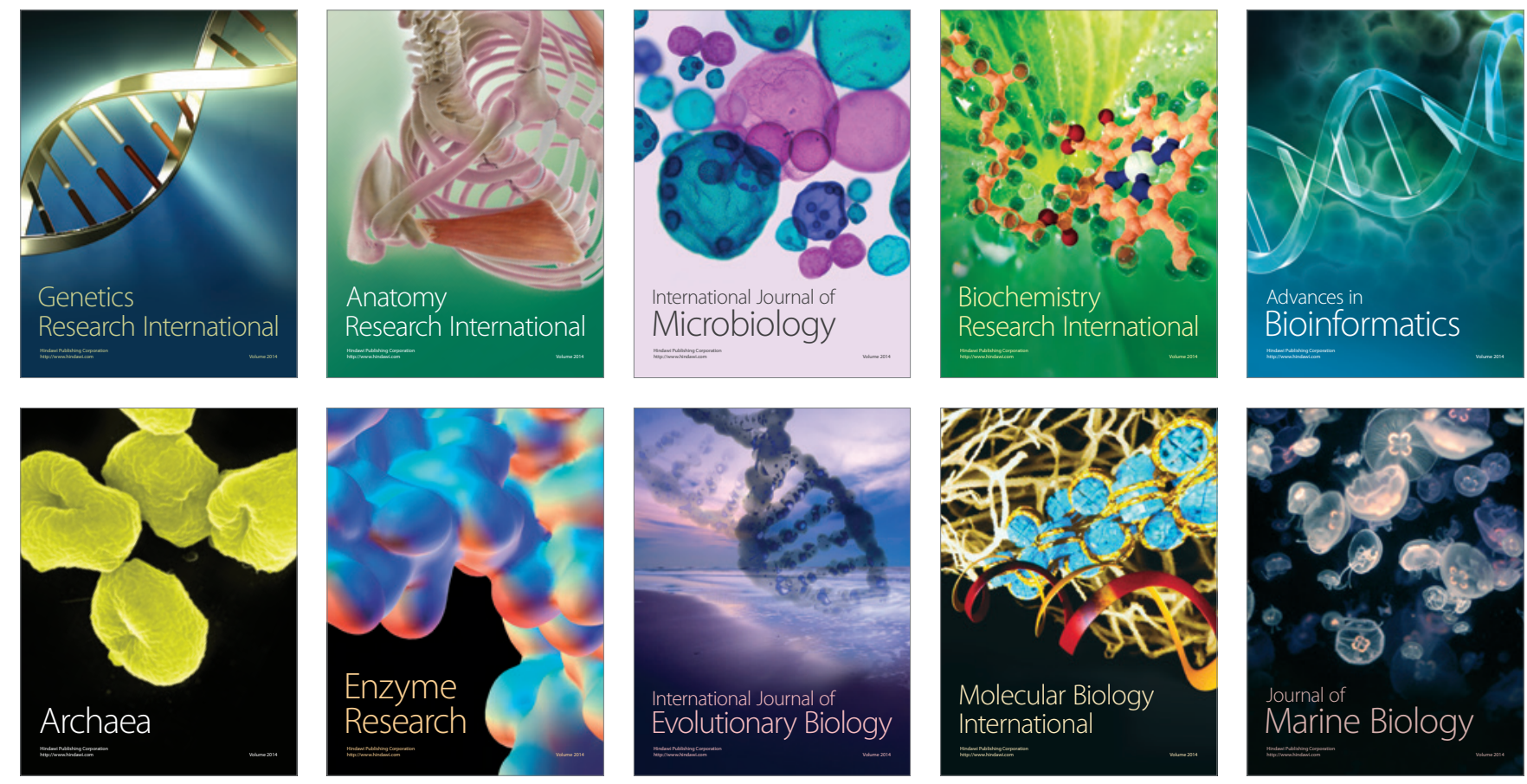